\title{
Adaptação à Separação Parental: Um Estudo Exploratório Qualitativo das Perspetivas de Jovens Adultos com Pais Separados e de Magistrados do Tribunal de Família e Menores
}

\author{
Adjustment to Parental Separation: A Qualitative and Exploratory Study of the \\ Perspectives of Young Adults with Separated Parents and Family Court Magistrates
}

\author{
Leonor Cunha $^{1}$ e Maria Teresa Ribeiro ${ }^{2}$
}

\begin{abstract}
Resumo
Partindo das lentes da psicologia sistémica, o presente estudo exploratório qualitativo propõe-se estudar as perspetivas de jovens adultos com pais separados e de magistrados do Tribunal de Família e Menores (TFM) acerca da adaptação à separação parental. Foram realizadas entrevistas semi-estruturadas a 10 jovens adultos com pais separados e 10 magistrados do TFM, analisadas através dos procedimentos de análise temática indutiva e dedutiva. Os resultados evidenciaram (1) o papel central da relação com e entre os pais na adaptação à separação parental, (2) a importância da relação do sistema familiar com os sistemas em que está inserido nesta fase, (3) a pertinência de pensar o papel dos magistrados nestes processos e (4) as potencialidades da mediação familiar como resposta às necessidades das famílias que passam por processos de separação. Os resultados são discutidos e analisados, tendo em conta as suas limitações e implicações.
\end{abstract}

Palavras-chave: separação parental, adaptação, fatores de risco e de proteção

\begin{abstract}
Through a systemic perspective, this exploratory study aims to contribute to a deeper understanding of children's adaptation process to parental separation. Based on the perspectives of young adults that experienced parental separation and of family court magistrates, the risk and protective factors of the adaptation process to parental separation were explored using qualitative methods. Semi structured interviews were conducted to these samples: 10 young adults which experienced parental separation and 10 family court magistrates. The content of the interviews were analysed through inductive and deductive thematic analysis. The results underline (1) the central role of the relationship with and between parents to this adjustment process; (2) the influence of the relationship between the family and other systemic levels; (3) the important role of family court magistrates in this processes and (4) the advantages of Family Mediation to respond to the needs of these families. Results, limitations of the study and practical implications are discussed.
\end{abstract}

Keywords: parental separation, adjustment, risk and protective factors

Nota: A amostra de magistrados é um recorte da amostra da investigação de doutoramento em curso: "Mediação Familiar em Portugal. A perceção dos Mediados, dos Mediadores e Magistrados.” Dr. ${ }^{a}$ Maria José Eusébio, com a qual houve a possibilidade de colaboração para a realização das entrevistas.

\footnotetext{
${ }^{1}$ Aluna do Doutoramento Inter-universitário Psicologia Clínica da Família e Intervenção Familiar das Faculdades de Psicologia e Ciências da Educação da Universidade de Coimbra e da Faculdade de Psicologia da Universidade de Lisboa.

Correspondência: Faculdade de Psicologia da Universidade de Lisboa, Alameda da Universidade, 1649-013 Lisboa, Portugal. E-mail: leonorgsilva@hotmail.com

${ }^{2}$ Professora Associada da Faculdade de Psicologia da Universidade de Lisboa, Coordenadora Mestrado do Núcleo de Psicologia Clínica Sistémica, Co-coordenadora do Doutoramento Inter-universitário em Psicologia da Família e Intervenção Familiar (PIDFIF), Co-coordenadora da Pós-Graduação em Psicologia e Intervenção em Crise e Emergência.
} 


\section{Introdução}

Uma das principais alterações demográficas que se tem verificado nas famílias portuguesas ao longo das últimas décadas é o grande aumento do número de divórcios (Pordata, 2014) e separações. Dada a dimensão deste fenómeno, que se estende por vários países do mundo ocidental, com impacto na vida de muitas famílias e profissionais que com elas trabalham (Amato, 2000), o tema da adaptação à separação parental tem suscitado muito interesse e investimento por parte dos investigadores de diversas áreas que, através de diferentes metodologias e paradigmas têm contribuído para a produção do sólido corpo de investigação atualmente existe (e.g., Amato, 2000; Kushner, 2009).

Através de vários estudos de revisão de literatura na área da Psicologia acerca deste tema (Amato, 2000; Birnbaum \& Saini, 2013; Gately \& Schwebel, 1991; Holt, 2016; Kushner, 2009; Peck \& Manocherian, 1989) é possível distinguir três correntes de investigação. Os primeiros estudos começaram por estar assentes numa conceptualização negativa do divórcio e da separação parental, com o enfoque nas suas consequências negativas (Blankenhorn, 1995). Como reação à anterior, emergiu uma nova corrente de investigação que enquadrou o divórcio como solução para problemas familiares, realçando as consequências positivas (Ahrons, 2008). A corrente mais recente da investigação nesta área adotou uma perspetiva mais complexa $\mathrm{e}$ integradora dos conhecimentos gerados no âmbito das correntes anteriores, conceptualizando assim a separação conjugal como um processo complexo que começa antes da separação efetiva do casal e que vai além da mesma (Amato, 2000). Postula ainda que a separação conjugal corresponde a um momento de crise no ciclo de vida familiar, pelo que requer um processo de adaptação exigente que assume configurações únicas, dependentes da interação de vários fatores (Amato, 2000).

$\mathrm{Na}$ presente investigação, a conceptualização da separação parental enquadra-se nesta última corrente de investigação por se considerar como uma rutura que ocorre no ciclo de vida familiar, complexificando as tarefas de desenvolvimento da família (Alarcão, 2002; Peck \& Manocherian, 1989; Alarcão, 2007). A Psicologia da Família, alicerçada na Teoria Geral dos Sistemas de Ludwig von Bertalanffy (1950), tem trazido diversos contributos de grande riqueza a nível científico, teórico e prático (Magnavita, 2012) através da sua dimensão holística, complexa e integrativa acerca da família, definindo-a como um sistema de interação e articulação permanente entre os componentes internos e os outros sistemas em que está inserida (Alarcão, 2002). Para ter acesso a uma perspetiva da adaptação à separação parental que abranja esta complexidade é pertinente ter em consideração o Modelo Ecológico de Bronfenbrenner (1979), que postula que os fenómenos relacionados com o desenvolvimento humano podem ser compreendidos de forma mais completa quando a investigação parte de uma perspetiva ecológica acerca das propriedades das pessoas e dos contextos, das estruturas e dos processos que ocorrem dentro de cada contexto e entre eles. E que, assim, os diversos contextos que influenciam e são influenciados pelo desenvolvimento humano são interdependentes e alvo de uma análise sistémica (Bronfenbrenner, 1986). Autores como Gately e Schwebel (1991) utilizaram uma perspetiva ecológica para a análise e discussão dos fatores de proteção e risco na adaptação ao divórcio parental.

A conceptualização da separação conjugal como um processo de crise familiar, fez com que muitos autores recorressem a modelos de stress para compreender os percursos de adaptação à separação parental (Amato, 2000; Gately \& Schwebel, 1991; Kelly \& Emery, 2003), tendo em conta o funcionamento do sistema familiar antes da crise e no momento da crise, os stressores e os fatores moderadores, que determinam a forma como a família se adapta à crise.

Dado que a forma como os filhos se adaptam à separação parental é fortemente influenciada pelas interações e relações entre os fatores de risco e de proteção a nível individual, familiar, e extrafamiliar em cada trajetória de desenvolvimento, torna-se pertinente olhar para a literatura.

Estes fatores têm sido organizados e estudados de diversas formas. Em relação às características dos filhos é apenas de destacar que Hetherington e Stanley-Hagan (1999) concluíram, através da revisão de vários estudos, que os filhos 
que vivem durante menos tempo períodos de grande conflito conjugal estão mais bem adaptados. Lansford (2009) justifica as diferenças pouco significativas da idade dos filhos no momento do divórcio/separação para a sua adaptação através das singularidades que o impacto deste acontecimento tem em cada fase do ciclo de vida. Assim, para compreender a influência da idade dos filhos na adaptação à separação dos pais é necessário ter em conta a trajetória anterior de desenvolvimento dos filhos, a fase de desenvolvimento em que se encontram na altura do divórcio/separação e as tarefas que enfrentam nesse momento, bem como o modo como o divórcio/separação influenciará as fases de desenvolvimento ao longo da vida.

A influência de fatores de nível microssistémico na adaptação à separação parental tem sido muito estudada (Amato, 2000; Kushner, 2009): as relações entre pais e filhos (EldarAvidan, Haj-Yahia, \& Greenbaum, 2009), a parentalidade e coparentalidade, as relações entre os pais e no sistema familiar (Di Stefano \& Cry, 2014; Friendly \& Grolnick, 2008; Holt, 2016; Kelly \& Emery, 2003; Lamela, Figueiredo, Bastos, \& Feinberg, 2016; Lansford, 2009;). O envolvimento dos dois pais na vida dos filhos e uma boa relação com ambos os pais, caracterizada por apoio emocional, uma comunicação frequente, clara e aberta e uma definição de papéis adequada são apresentados por muitos autores como fatores protetores centrais na adaptação à separação parental (Holt, 2016; Lamela et al., 2016), com exceção das situações em que o afastamento do filho de um dos pais, pelas consequências negativas que essa relação trazia, se torna protetora (Kelly \& Emery, 2003). Nielsen (2013, 2014) acrescenta que a quantidade de tempo que os pais não residentes passam com os filhos está significativamente relacionada com a qualidade e a durabilidade da relação pai/mãe-filhos e com consequências positivas na adaptação dos filhos.

É atribuído um papel central aos estilos parentais na adaptação à separação dos pais (Bastaits \& Mortelmans, 2017; Holt, 2016; Lamela et al., 2016; Vélez et al., 2011), sendo que um estilo parental autoritativo antes, durante e depois do divórcio está relacionado com a boa adaptação dos filhos (e.g., Amato, 2000; Di Stefano \& Cry, 2014; Gately \& Schwebel, 1991;
Lansford, 2009). A coparentalidade e a relação entre os pais depois da separação, embora mais associadas aos fatores de risco, são definidas na literatura como protetoras nas situações em que há uma diminuição do conflito depois da separação e quando a relação entre pais é de cooperação, consistência, apoio, divisão de responsabilidades e paz (e.g., Lamela et al., 2016; Gately \& Schwebel, 1991; Vélez et al., 2011).

Os fatores do microssistema mais vezes associados a dificuldades na adaptação à separação parental são a alta conflitualidade entre os pais antes, durante e depois da separação e quando o conflito é aberto, em frente aos filhos, sobre eles e quando traz conflitos de lealdade (Amato, 2000; Davies, Martin, \& Cicchetti, 2012; Kelly \& Emery, 2003; Kushner, 2009; Lansford, 2009; Martínez-Pampliega et al., 2015). Na relação pais-filhos, o afastamento de um dos pais e a degradação das relações com os pais na sequência da separação são apontados na literatura como fatores de risco relevantes (Bastaits \& Mortelmans, 2017; Eldar-Avidan et al., 2009; Gately \& Schwebel, 1991; Holt, 2016; Kelly \& Emery, 2003; Lansford, 2009; Rodgers \& Rose, 2002). Outro fator relevante é degradação da qualidade da parentalidade depois da separação, sobretudo a menor disponibilidade emocional, a monitorização mais fraca ou inconsistente dos filhos, dificuldades em impor regras e limites, bem como situações em que o conflito parental dificulta a parentalidade do outro progenitor (Amato, 2000; Eldar-Avidan et al., 2009; Hetherington \& Stanley-Hagan, 1999; Kelly \& Emery, 2003; Lansford, 2009; Rodgers \& Rose, 2002).

Os fatores de nível extrafamiliar estão menos estudados e há menos informação acerca da sua influência neste processo (Hetherington \& Stanley-Hagan, 1999; Rodgers \& Rose, 2002). Ainda assim, há alguns estudos que referem as condições sócio-económicas, a escola, os amigos, a família alargada e as atividades extracurriculares como relevantes na adaptação à separação (Amato, 2000; Eldar-Avidan et al., 2009; Gately \& Schwebel, 1991; Kushner, 2009; Lansford, 2009; Rodgers \& Rose, 2002). Verificou-se que uma grande diminuição das condições económicas na sequência da separação, sobretudo quando associada à não contribuição económica de um 
dos pais, constitui-se como um fator de risco (Amato, 2000; Eldar-Avidan et al., 2009; Gately \& Schwebel, 1991; Lansford, 2009). Por outro lado, a ligação à escola, o apoio de amigos e família alargada e o envolvimento em atividades extracurriculares surgem na literatura como fatores protetores (Amato, 2000; Eldar-Avidan et al., 2009; Gately \& Schwebel, 1991; Kushner, 2009; Rodgers \& Rose, 2002).

Em relação ao sistema legislativo que está na base das decisões acerca da vida dos filhos na sequência da separação parental, Gately e Schwebel (1991) identificam como protetores os procedimentos de resolução de conflitos não adversariais e extrajudiciais, como a mediação familiar, que potenciam a concretização do superior interesse da criança. A mediação familiar configura-se, assim, como uma resposta que vai ao encontro das necessidades das famílias que passam por um processo de separação.

Questões como a modalidade de residência dos filhos têm também sido alvo de grande discussão e mediatização (Ricci, 2004), sendo que de acordo com Amato (2000, p. 1281) "uma conclusão sensata é a de que nenhuma modalidade de residência é a melhor para todas as crianças", acrescentando que a relação pais-filhos e a coparentalidade parecem estar mais fortemente relacionadas com a adaptação e bem-estar dos filhos do que o tipo de residência. De acordo com Kelly e Emery (2003), um dos fatores protetores na adaptação à separação dos pais é a satisfação dos filhos em relação à modalidade de residência e de exercício das responsabilidades parentais.

De acordo com a literatura, a influência e impacto destes fatores de risco e proteção deve ser vista no contexto de uma trajetória de desenvolvimento individual, familiar e social, que começa antes da separação parental com potencial de desembocar em formas de adaptação únicas, que devem ser analisadas nos seus contextos e de forma completa.

Apesar da construção deste sólido corpo de investigação ao longo das últimas décadas, Hetherington e Stanley-Hagan (1999) referiram ainda a necessidade de investigações acerca das influências das relações entre os vários subsistemas familiares na adaptação dos filhos à separação parental através de uma perspetiva sistémica, bem como o impacto dos fatores extrafamiliares. Friendly e Grolnick (2008) apontaram também para a necessidade de um conhecimento mais aprofundado dos mecanismos e processos que explicam a adaptação à separação parental e, de acordo com Kelly e Emery (2003), com especial incidência nos fatores protetores.

Dado que, nas últimas décadas, a separação conjugal se tem tornado cada vez mais frequente nas famílias da nossa sociedade - no ano de 2013 registaram-se 70.4 divórcios por cada 100 casamentos (Pordata, 2017b) e o aumento contínuo de núcleos familiares monoparentais, 436.375 em 2016 (Pordata, 2017a) -, que os acordos de Regulação de Responsabilidades Parentais (RRP) têm vindo a aumentar - 15275 processos RRP iniciados em 2011 (Associação Portuguesa para a Igualdade Parental e Direito dos Filhos, 2012) - tal como os incumprimentos e alterações e que todos são submetidos a aprovação pelo Ministério Público (Fialho, 2013), torna-se pertinente contribuir para uma compreensão aprofundada desta realidade.

A presente investigação, de carácter exploratório e comparativo, propõe-se (1) conhecer as perceções de magistrados do Tribunal de Família e Menores (TFM) acerca dos principais fatores de proteção e de risco na adaptação à separação parental; (2) aceder às perceções de jovens adultos com pais separados acerca dos fatores de risco e proteção na adaptação à separação parental; e (3) comparar as perceções de ambas as amostras, de modo a que se possam levantar hipóteses explicativas acerca do impacto dos diversos fatores no processo de adaptação à separação parental bem como das suas implicações práticas.

\section{Método}

O presente estudo exploratório é de natureza qualitativa, o que permitiu aceder às perceções dos dois grupos de participantes quanto aos fatores de risco e proteção na adaptação à separação parental, comparando-as e conduzindo a um alargamento de perspetivas que serviu a complexidade do tema.

\section{Participantes}

O processo de seleção das amostras utilizadas 
nesta investigação foi não-aleatório, mais concretamente, amostragem por conveniência e por bola de neve (Vanderstoep e Johnston, 2009).

A amostra dos magistrados do TFM é um recorte da amostra de um estudo de doutoramento da Dr. ${ }^{a}$ Maria José Eusébio ${ }^{1}$, com quem houve a possibilidade de colaboração na realização das entrevistas. A seleção da amostra foi feita através do contacto com os Tribunais de Família e Menores de Lisboa, Cascais, Sintra, Barreiro e com o Centro de Estudos Judiciários, solicitando a participação de magistrados do Tribunal de Família e Menores numa entrevista, de forma completamente voluntária e confidencial. Como critérios para inclusão dos magistrados na amostra era apenas necessário que trabalhassem nesta área ou tivessem trabalhado recentemente (desde há menos de 1 ano).

Para a segunda amostra foi pedida a colaboração de jovens adultos, sendo os critérios de inclusão terem idades compreendidas entre os 18 e os 28 anos (Erikson, 1963) e serem filhos de pais separados há mais de dois anos (Peck \& Manocherian, 1989; Wallerstein, 1983).

Assim, a investigação contou com o total de 20 participantes $(\mathrm{N}=20)$, divididos em duas amostras: uma constituída por 10 magistrados do TFM $(\mathrm{N}=10)$ e outra por 10 jovens adultos $(\mathrm{N}=10)$, com idades compreendidas entre os $18 \mathrm{e}$ 28 anos $(M=23.7, D P=2.41)$ e com pais separados há mais de dois anos. A dimensão das amostras está relacionada com o facto de ter sido atingida a saturação teórica, sendo que os dados dos 2 últimos participantes das amostras não acrescentaram novas categorias.

Os 10 magistrados entrevistados, 6 do sexo feminino e 4 do sexo masculino, tinham idades entre os 38 e os 61 anos $(M=51.9, D P=7.06)$. Destes participantes, 6 eram Procuradores do Ministério Público e 4 Juízes de Direito que exerciam as suas funções na área da Família e Menores desde entre 2 e 21 anos $(M=10.5$, $D P=6.84)$. As entrevistas foram realizadas nos Tribunais de Lisboa, Sintra, Cascais, Barreiro e no Conselho Superior de Magistratura (CEJ).

Dos 10 jovens adultos entrevistados, 6 são do sexo feminino e 4 do sexo masculino. Todos os elementos da amostra estavam ou tinham estado no ensino superior e o período de tempo decorrido desde a separação dos pais era entre os 4 e os 27 anos $(M=15.8, D P=7.42)$. Para 4 deles o acordo de RRP foi realizado em tribunal e no caso de 6 participantes foi decidido entre os pais, sendo que 7 deles ficaram a viver com a mãe, 2 ficaram com residência alternada e 1 deles com outro familiar.

\section{Procedimento}

Todos os participantes, de ambas as amostras, leram e assinaram um consentimento informado com informação detalhada acerca dos procedimentos do estudo, garantindo a participação voluntária e a confidencialidade. Depois disto foi realizada uma entrevista semiestruturada com cada um dos participantes.

A amostra de magistrados do TFM foi um recorte da amostra de uma investigação de doutoramento em curso. A seleção da amostra foi feita através do contacto com os Tribunais de Família e Menores, fazendo um apelo à participação dos magistrados.

Quanto à amostra dos jovens adultos filhos de pais separados, importa referir que a seleção desta faixa etária, dos 18 e os 28 anos, para a amostra da investigação relaciona-se com as potencialidades da fase de desenvolvimento do jovem adulto, nomeadamente a consolidação e integração da autonomia e da identidade (Alarcão, 2002) conquistadas através uma maior diferenciação emocional das figuras parentais, o que permite também um pensamento mais objetivo e maduro acerca da relação estabelecida com os pais e uma visão crítica da parentalidade que exerceram (Guedeney \& Guedeney, 2004). Além disso, segundo Erikson (1963), com o estabelecimento de relacionamentos amorosos mais maduros ocorre uma revisão dos modelos conjugais, nomeadamente o dos pais. Mais ainda, em termos éticos, o amadurecimento das estruturas emocionais e cognitivas de um jovem adulto torna o acesso a estes temas mais seguro em termos de eventuais consequências negativas da participação no estudo, para o que contribui também o facto dos pais dos jovens da amostra estarem separados há período superior a dois anos (Peck \& Manocherian, 1989; Wallerstein, 1983). Por outro lado, esta é também uma faixa etária menos estudada na temática da adaptação à separação parental e com grandes potencialidades (Amato, Loomis, \& Booth, 1995; Eldar-Avidan et al., 2009). O processo de amostragem dos jovens 
adultos foi iniciado com um apelo à rede social alargada de uma das autoras, passando depois a uma amostragem por bola de neve (no fim da entrevista os participantes eram convidados a indicar alguém que pudesse ter interesse em participar).

\section{Instrumentos}

Foram utilizados dois guiões de entrevistas semi-estruturadas, um para cada amostra, dos quais constava um pequeno questionário sóciodemográfico. No caso das entrevistas realizadas aos magistrados do TFM recolheram-se informações relativas ao sexo, idade, tipo de magistratura, tempo de trabalho na área da família e menores, formação complementar na área e tribunal onde desempenham funções. Aos jovens adultos foi perguntado o sexo, a idade, a escolaridade, o tempo decorrido desde a separação dos pais e com quem ficaram a residir depois da separação parental.

Assim, todos os participantes realizaram uma entrevista semi-estruturada que, partindo de temas e questões comuns, permitiu aprofundar a compreensão das perceções dos participantes e gerir as temáticas expostas com flexibilidade, trazendo vantagens no acesso às perceções dos participantes acerca das suas experiências pessoais (Marks \& Yardley, 2004).

As entrevistas semi-estruturadas realizadas aos magistrados do TFM seguiram um guião ${ }^{1}$ com 4 blocos temáticos principais: 1) processos de regulação das responsabilidades parentais, e.g., “como são trabalhados estes processos?"; 2) conflito, e.g., "que conflitos surgem na regulação das responsabilidades parentais?"; 3) mediação familiar, e.g., "que efeitos/impactos tem a mediação familiar nos casos de regulação das responsabilidades parentais?" e 4) menores, e.g., "que atitudes dos pais facilitam ou dificultam a adaptação dos filhos à separação?".

Com base nos temas que emergiram da revisão de literatura e nos objetivos do estudo foi construído o guião da entrevista semi-estruturada realizada aos jovens adultos, composto por 3 blocos temáticos: 1) a separação/divórcio, e.g., "Que mudanças traz uma separação ou divórcio?";

2) a adaptação dos filhos à separação parental, e.g., "Como devem ser tomas as decisões acerca da vida dos filhos depois da separação?” e 3) consequências da separação parental, e.g.: "Quais as consequências negativas e positivas que a separação dos pais pode trazer à vida dos filhos?

A análise dos dados foi realizada, numa primeira fase através da análise temática indutiva, procurando identificar padrões nos conteúdos manifestos e latentes das entrevistas (Braun \& Clarke, 2006; Marks \& Yardley, 2004). Numa segunda fase, partindo da análise da árvore de categorias que emergiu, tornou-se pertinente organizar os dados através do Modelo Ecológico de Bronfenbrenner (1979), ou seja, utilizar a análise temática dedutiva (Braun \& Clarke, 2006). Todo o processo de análise de dados foi realizado com recurso ao software Qualitative Solutions Research (QSR) NVivo 10.

\section{Resultados}

A partir da análise de dados anteriormente descrita foi possível chegar a resultados muito enriquecedores, expostos em seguida. Para cada categoria o número de pessoas e o número de referências codificados estarão entre parêntesis. $\mathrm{Na}$ comparação dos resultados das duas amostras o número de pessoas que referiram a categoria será identificado por um $\mathrm{M}$ para os magistrados $\mathrm{e}$ por um $\mathrm{J}$ para os jovens adultos. Quanto às citações dos participantes, a letra identifica o sexo e o número a idade.

\section{Fatores de Proteção e de Risco na Adaptação à Separação Parental}

Os resultados que dizem respeito às perspetivas dos fatores de risco e proteção foram organizados com recurso ao Modelo Ecológico de Bronfenbrenner (1979), pela coerência e sentido que o modelo lhes trouxe. O microssistema encontra-se aqui definido como os contextos em que os filhos estão diretamente envolvidos e com impacto direto nesta adaptação (e.g., relação pais/filhos) e o mesossistema como a relação entre estes contextos mais diretos (e.g., relação com a família alargada). No exossistema estão inseridos os contextos nos quais os filhos de pais separados não estão diretamente envolvidos mas com impacto na sua adaptação à separação parental 
Quadro 1. Árvore de categorias dos fatores de proteção identificados pelos magistrados

\begin{tabular}{|c|c|c|}
\hline Fatores de proteção & $\mathrm{N}^{\circ}$ de pessoas & $\mathrm{N}^{\circ}$ de referências \\
\hline \multicolumn{3}{|l|}{ Microssistema } \\
\hline Relação pais-filhos & 9 & 16 \\
\hline Atitudes que protegem os filhos da situação & 8 & 8 \\
\hline Maior envolvimento possível dos dois pais na vida dos filhos & 4 & 6 \\
\hline Pais que ouvem os filhos & 1 & 1 \\
\hline Pais que separam a parentalidade da conjugalidade & 1 & 1 \\
\hline Relação entre pais & 9 & 15 \\
\hline Respeito & 4 & 6 \\
\hline Tempo decorrido desde a rutura conjugal & 4 & 5 \\
\hline Comunicação eficaz entre os pais & 2 & 2 \\
\hline Separar parentalidade de conjugalidade & 2 & 2 \\
\hline Boa relação com padrastos ou madrastas & 1 & 1 \\
\hline \multicolumn{3}{|l|}{ Mesossistema } \\
\hline Apoio da família alargada & 6 & 8 \\
\hline Ligação com a escola & 3 & 3 \\
\hline Envolvimento em atividades extracurriculares & 1 & 1 \\
\hline Proximidade de equipamentos de saúde & 1 & 1 \\
\hline \multicolumn{3}{|l|}{ Exossistema } \\
\hline Meios utilizados para trabalhar os processos com efeito protetor & 10 & 121 \\
\hline Magistrado & 10 & 95 \\
\hline Características, experiências, valores e práticas pessoais & 10 & 70 \\
\hline Práticas de negociação & 5 & 12 \\
\hline Atitude empática & 5 & 7 \\
\hline Ferramentas gestão de conflito & 5 & 6 \\
\hline $\begin{array}{l}\text { Recurso a Instituições Particulares de Solidariedade Social (IPSS) e a Centros de } \\
\text { Apoio Familiar e Aconselhamento Parental (CAFAP) }\end{array}$ & 6 & 8 \\
\hline Instauração de Processos de Promoção e Proteção & 3 & 10 \\
\hline Estágios de psicologia & 3 & 7 \\
\hline Polícia: averiguação célere das condições sócio-económicas & 1 & 1 \\
\hline Critérios de tomada de decisão protetores & 10 & 65 \\
\hline Estabilidade & 8 & 18 \\
\hline Relação entre os pais & 8 & 16 \\
\hline Maior envolvimento possível dos dois pais na vida dos filhos & 6 & 7 \\
\hline Acordo entre os pais & 6 & 7 \\
\hline Adaptação à realidade da família & 5 & 7 \\
\hline Pais com igualdade de oportunidades & 3 & 3 \\
\hline Superior interesse da criança & 2 & 2 \\
\hline Audição da criança & 1 & 3 \\
\hline Existência de uma figura de referência principal & 1 & 1 \\
\hline Regime regra da lei & 1 & 1 \\
\hline Sucesso nos processos de RRP & 10 & 29 \\
\hline Pais fazerem o acordo entre si & 7 & 13 \\
\hline Compreender e assegurar o superior interesse das crianças & 6 & 10 \\
\hline Processos que não voltam a tribunal & 4 & 4 \\
\hline Reconciliação nas relações pais-filhos & 1 & 2 \\
\hline Advogados interessados na resolução do conflito & 4 & 6 \\
\hline \multicolumn{3}{|l|}{ Macrossistema } \\
\hline Propostas de fatores protetores no sistema judicial & 7 & 38 \\
\hline Equipa multidisciplinar no tribunal & 7 & 29 \\
\hline Entidades para supervisão de visitas em articulação com o tribunal & 2 & 7 \\
\hline Entidades que trabalhem as relações pais-filhos & 1 & 2 \\
\hline Mudanças no papel do pai: maior envolvimento & 1 & 1 \\
\hline
\end{tabular}

(e.g., decisões judiciais). O macrossistema referese aos contextos ideológico, cultural e social, que moldam a forma como este processo é vivido e percebido em sociedade, o que traz impactos para este processo de adaptação (Bronfenbrenner, 1979).

\section{Fatores de proteção identificados pelos magistrados}

Em relação aos fatores de proteção identificados pelos magistrados, da análise temática resultaram 47 categorias interrelacionadas, organizadas num sistema hierárquico onde existem 13 categorias principais, expostas no Quadro 1.

Ao nível do microssistema, os fatores protetores que mais magistrados identificaram foram a boa relação pais-filhos (9 pessoas-16 referências: 9p-16r) e a boa relação entre os pais (9p-15r). Na categoria boa relação pais-filhos surgiram temas como as atitudes que protegem os filhos da situação (8p-8r) e o maior envolvimento 
Quadro 2. Árvore de categorias dos fatores de risco identificados pelos magistrados

\begin{tabular}{|c|c|c|}
\hline Fatores de risco & $\mathrm{N}^{\mathrm{o}}$ de pessoas & $\mathrm{N}^{\circ}$ de referências \\
\hline \multicolumn{3}{|c|}{ Microssistema } \\
\hline Relação entre pais & 8 & 39 \\
\hline Conflito inter-parental & 8 & 37 \\
\hline Expor e envolver os filhos no conflito dos pais & 8 & 20 \\
\hline Dificultar a relação com o outro progenitor & 4 & 9 \\
\hline Forma de descarregar as frustrações & 3 & 5 \\
\hline Centrados apenas no dinheiro & 2 & 2 \\
\hline Relações cortadas & 1 & 1 \\
\hline Idealização da reconciliação dos pais & 2 & 2 \\
\hline Filhos vistos como propriedades dos pais & 2 & 3 \\
\hline Má relação com padrastos ou madrastas & 1 & 1 \\
\hline \multicolumn{3}{|c|}{ Mesossistema } \\
\hline Família alargada tomar partidos & 5 & 8 \\
\hline \multicolumn{3}{|c|}{ Exossistema } \\
\hline Motivos de conflito nos processos RRP & 10 & 45 \\
\hline Maior conflitualidade & 10 & 21 \\
\hline Famílias com mais condições sócio-económicas & 8 & 9 \\
\hline Contactos e residência & 7 & 11 \\
\hline Questões económicas & 1 & 1 \\
\hline Mais frequente & 10 & 16 \\
\hline Pensão de alimentos & 8 & 12 \\
\hline Visitas & 3 & 4 \\
\hline Mais grave & 4 & 8 \\
\hline Violência doméstica e familiar & 4 & 5 \\
\hline Relações disfuncionais & 2 & 2 \\
\hline Problemas de saúde mental & 1 & 1 \\
\hline Meios utilizados para trabalhar os processos & 10 & 107 \\
\hline Magistrado & 10 & 79 \\
\hline Características, experiências, valores e práticas pessoais & 10 & 70 \\
\hline Risco & 4 & 9 \\
\hline Tempo de espera pelos relatórios da segurança social & 9 & 19 \\
\hline Demora nas perícias do Instituto de Medicina Legal & 6 & 9 \\
\hline \multicolumn{3}{|l|}{ Residência } \\
\hline Alternada & 7 & 15 \\
\hline Desvantagens & 3 & 3 \\
\hline Instabilidade habitacional & 3 & 3 \\
\hline Vantagens & 2 & 2 \\
\hline Manutenção da relação com os dois pais & 2 & 2 \\
\hline Com um progenitor & 3 & 3 \\
\hline Vantagens & 2 & 2 \\
\hline Ter o seu espaço & 1 & 1 \\
\hline Modelo educacional sólido e coerente & 1 & 1 \\
\hline Desvantagens & 2 & 2 \\
\hline Menor influência e proximidade do progenitor não residente & 2 & 2 \\
\hline Advogados interessados em fomentar o conflito & 6 & 10 \\
\hline Modelos relacionais disfuncionais & 2 & 2 \\
\hline Audição da criança em tribunal & 1 & 1 \\
\hline Desinteresse das funções parentais & 1 & 1 \\
\hline \multicolumn{3}{|c|}{ Macrossistema } \\
\hline Contexto sócio-económico e laboral & 6 & 18 \\
\hline Política social & 4 & 27 \\
\hline Ineficácia do sistema social & 3 & 24 \\
\hline Excesso de regulação e falta de eficácia & 2 & 2 \\
\hline Desvalorização da pessoa humana & 1 & 1 \\
\hline Multiculturalidade & 3 & 5 \\
\hline Diferenças na noção de família e papéis familiares & 2 & 2 \\
\hline Poucas soluções adaptadas a emigrantes & 1 & 2 \\
\hline Diferenças na forma de viver os conflitos & 1 & 1 \\
\hline Cultura de conflito e de individualidade & 2 & 3 \\
\hline Papéis de pai e de mãe rígidos & 2 & 3 \\
\hline
\end{tabular}

possivel dos dois pais na vida dos filhos (4p-6r). A boa relação entre os pais apareceu ligada ao respeito (4p-6r), ao tempo decorrido desde a rutura conjugal (4p-5r), à comunicação eficaz entre os pais (2p-2r), e à separação entre conjugalidade $e$ parentalidade (2p-2r).

"Às vezes o ter passado algum tempo também ajuda porque o problema não é com as crianças 
mas é entre os pais porque não resolveram bem a separação e as coisas entre eles. No início [os pais] podem nem perceber muito bem o que é mas depois de fazerem o luto da relação $e$ compreenderem, aceitam e já é mais fácil conseguir um acordo." (F, 61).

No mesossistema, 6 dos magistrados identificaram como fator protetor o apoio $d a$ família alargada (6p-8r):

“...é terem o suporte da família alargada. É importante que as pessoas não fiquem isoladas após o divórcio e que o resto da comunidade consiga dar apoios. Mas muito importante é o da família alargada." (F, 54).

Em torno do tema do trabalho dos processos de regulação das responsabilidades parentais os magistrados identificaram alguns fatores de proteção, incluídos no exossistema. Em relação aos meios utilizados para trabalhar os processos com efeito protetor, todos falaram acerca do papel do magistrado (10p-95r) ou seja, de serem eles próprios uma ferramenta deste trabalho. As formas de trabalho do magistrado mais percecionadas pelos próprios como protetoras foram a atitude empática $(5 \mathrm{p}-7 \mathrm{r})$, as práticas de negociação (5p-12r), ferramentas gestão de conflito (5p-6r), contudo todas elas foram associadas pelos magistrados a características, experiências, valores e práticas pessoais (10p76r), o que foi referido como tendo o potencial para ser fator de risco e proteção simultaneamente:

"Pronto, em primeiro lugar tenta-se um acordo entre os pais e isso depende muito do "jeito" dos magistrados, porque é mesmo assim. Há uns que têm mais jeito para obter o acordo do que outros." (M,55).

$\mathrm{O}$ recurso a Instituições Particulares de Solidariedade Social (IPSS) e a Centros de Apoio Familiar e Aconselhamento Parental (CAFAP) (6p-8r) foi também referido como protetor.

No que diz respeito a critérios de tomada de decisão protetores, os magistrados referiram a estabilidade (8p-18r):

“...para a criança é muito muito bom e muito protetor naquela fase manter, dentro do possível, tudo igual. Ou seja, manter a escola, manter os amigos, manter relações familiares." (F,38)

A relação entre os pais (8p-16r), o maior envolvimento possível dos dois pais na vida dos filhos (6p-7r), o acordo entre os pais (6p-7r) e da adaptação à realidade da família (5p-7r). A maior parte dos magistrados relacionou casos de sucesso a situações em que os pais fazem o acordo entre si (7p-13r) e em que se consegue compreender $e$ assegurar o superior interesse das crianças (6p10r) e apontaram também a existência de advogados que fomentam a resolução dos conflitos (4p-6r) como um fator protetor.

Em relação ao macrossistema, os magistrados falaram em propostas de fatores protetores no sistema judicial (7p-38r), com destaque para a existência de uma equipa multidisciplinar a funcionar no tribunal (7p-29r).

"Em casos em que a litigação é muita devia haver uma entidade em termos de mediação familiar, com psicólogos, uma equipa multidisciplinar... Penso que essas equipas deviam estar nos tribunais." (F, 61).

\section{Fatores de risco identificados pelos magistrados}

Quanto aos fatores de risco identificados pelos magistrados, da análise temática resultaram 56 categorias interrelacionadas, organizadas num sistema hierárquico onde existem 16 categorias principais:

A nível microssistémico, o fator de risco mais identificado pelos magistrados foi o conflito interparental (8p-37r), mais concretamente expor $e$ envolver os filhos no conflito dos pais (8p-20r) e dificultar a relação com o outro progenitor (4p-9r):

"Quer dizer, uma coisa continuada de um conflito permanente em que a criança é um objeto no meio da relação, a personalidade do miúdo está muito em perigo. E como é que pedem o desenvolvimento integral da criança nessas circunstâncias?" $(\mathrm{F}, 46)$.

No mesossistema os magistrados identificaram como fator de risco a família alargada tomar partidos (5p-8r) e, no exossistema, os que foram mais identificados pelos magistrados no que diz respeito ao trabalho dos processos de regulação das responsabilidades parentais foram o tempo de espera pelos relatórios da segurança social $(9 \mathrm{p}-19 \mathrm{r})$ e a demora nas perícias do Instituto de Medicina Legal (6p-9r), que associaram à demora na resolução dos processos. Quanto ao papel do próprio magistrado, de que todos falaram (10p- 
79r) mais uma vez como estando relacionado com características, experiências, valores e práticas pessoais (10p-70r), apenas 4 magistrados explicitaram o risco $(4 \mathrm{p}-9 \mathrm{r})$ que isso envolve neste tipo de trabalho:

"São situações muito complicadas. Há a experiência e o bom senso mas também podem ser uma coisa perigosa. Em geral a experiência ajuda muito mas depende muito dos juízes." (M, 55).

Apontaram ainda os advogados interessados em fomentar o conflito (6p-10r) como um risco nestas situações.

Acerca do conflito no âmbito dos processos os magistrados apontaram como fator de risco para a existência de mais conflitualidade as famílias com mais poder económico (8p-9r) e o desacordo nas questões de contactos e residência (7p-11r), embora o mais frequente sejam conflitos pela pensão de alimentos (8p-12r):

"Há uns anos atrás era mais as visitas mas já estamos num nível do básico: como é que eu o alimento? Básico do dinheiro, do dia-a-dia." (F,54).

No macrossistema os magistrados identificaram como fator de risco principal o contexto sócio-económico e laboral das famílias portuguesas (6p-18r).

\section{Fatores de proteção identificados pelos jovens adultos}

Em relação aos fatores de proteção identificados pelos magistrados, da análise temática resultaram 45 categorias interrelacionadas, organizadas num sistema hierárquico onde existem 14 categorias principais:

A nível microssistémico, os fatores protetores para a adaptação à separação parental mais identificados pelos jovens adultos filhos de pais separados foram a qualidade da relação entre os pais (10p-49r), que associaram à existência de respeito (7p-11r), de uma comunicação eficaz entre pais $(7 \mathrm{p}-14 \mathrm{r})$ e à separação entre conjugalidade e parentalidade (6p-9r):

"É muito bom mas é dificil de fazer, que é, garantir que, aos olhos da criança, o outro continua a ser muito bem visto e defendido." $(\mathrm{M}, 23)$.

Os jovens identificaram ainda como protetor uma boa relação pais-filhos (9p-26r) especificando a importância do maior envolvimento possível dos dois pais na vida dos filhos (7p-13r), do apoio emocional (6p-7r) e 3 jovens falaram ainda na importância da manutenção dos papéis e da parentalidade:

"...deve haver um máximo de participação dos pais na vida dos filhos, quando possível, e, no fundo, criarem, eles próprios, também rotinas novas sem que os papéis se invertam." (F,23).

Acerca da comunicação da decisão da separação os jovens apontaram como protetor a transmissão de informações e explicações claras acerca das mudanças (7p-14r), com uma linguagem e explicações adaptadas à idade dos filhos (5p-5r), transmitindo continuidade na relação com os pais e segurança (5p-10r) e feita pelos dois pais em conjunto (5p-7r).

Quanto a outros contextos protetores, a nível mesossistémico, os jovens referiram o apoio da família alargada (8p-15r), nomeadamente através da manutenção do sentido de pertença e do suporte emocional; o apoio dos amigos (7p-9r), a ligação à escola $(7 \mathrm{p}-14 \mathrm{r})$ :

"eu tive uma professora que... duas, que, numa altura em que eu estava mais em baixo, consegui falar com elas e elas ajudaram-me muito." (F,24).

Além disso, 5 jovens falaram concretamente acerca da importância da articulação escolafamília (5p-7r) e foi também referido o apoio de pessoas significativas (6p-8r) como os avós, irmãos ou namorado/a. As atividades extracurriculares foram ainda referidas como fator protetor por 4 jovens, por permitirem a abstração da situação e pelo sentimento de pertença. No que diz respeito às decisões tomadas acerca da vida dos filhos, a nível do exossistema, todos os jovens adultos falaram na importância de assegurar a continuidade na parentalidade $e$ coparentalidade pré e pós separação (10p-18r):

"Portanto, as decisões devem ser feitas da forma mais aproximadamente possível com o modo como eram feitos antes." (F,23)

Foram referidas ainda a necessidade de adequar as decisões às necessidades $e$ características das crianças e da família (8p-28r) e a estabilidade (6p-13r).

\section{Fatores de risco identificados pelos jovens adultos}

Em relação aos fatores de proteção identificados pelos magistrados, da análise temática 
Quadro 3. Árvore de categorias dos fatores de proteção identificados pelos jovens adultos

\begin{tabular}{|c|c|c|}
\hline Fatores de proteção & $\mathrm{N}^{\circ}$ pessoas & $\mathrm{N}^{\circ}$ referências \\
\hline \multicolumn{3}{|l|}{ Microssistema } \\
\hline Relação entre pais & 10 & 49 \\
\hline Respeito & 7 & 11 \\
\hline Comunicação eficaz entre os pais & 7 & 14 \\
\hline Separação entre conjugalidade e parentalidade & 6 & 9 \\
\hline Cooperação & 4 & 4 \\
\hline Amizade & 4 & 8 \\
\hline Fomentar a relação com o outro progenitor & 2 & 2 \\
\hline Presença dos dois em momentos importantes & 1 & 1 \\
\hline Comunicação da decisão da separação & 10 & 44 \\
\hline Informações e explicações claras acerca das mudanças & 7 & 14 \\
\hline Continuidade na relação com os pais e segurança & 5 & 10 \\
\hline Pelos dois pais em conjunto & 5 & 7 \\
\hline Linguagem e explicações adaptadas à idade dos filhos & 5 & 5 \\
\hline Reforçar que os filhos não têm culpa & 3 & 4 \\
\hline Explicar que é uma decisão definitiva & 2 & 3 \\
\hline Dizer que é o melhor para todos & 1 & 1 \\
\hline Relação pais-filhos & 9 & 26 \\
\hline Maior envolvimento possível dos dois pais na vida dos filhos & 7 & 13 \\
\hline Apoio emocional & 6 & 7 \\
\hline Manutenção dos papéis e da parentalidade & 3 & 5 \\
\hline Saber pedir ajuda aos pais & 1 & 1 \\
\hline Idade dos filhos no momento da separação & 3 & 5 \\
\hline Primeiros anos de vida & 3 & 4 \\
\hline Jovens adultos & 1 & 1 \\
\hline Apoio dos irmãos & 2 & 2 \\
\hline Boa relação com padrastos e madrastas & 1 & 5 \\
\hline \multicolumn{3}{|l|}{ Mesossistema } \\
\hline Apoio da família alargada & 8 & 15 \\
\hline Apoio emocional & 4 & 5 \\
\hline Relações saudáveis entre as famílias do pai e da mãe & 3 & 3 \\
\hline Afastar da situação & 2 & 3 \\
\hline Avós - apoio e pertença & 2 & 3 \\
\hline Não falar mal do pai ou da mãe & 1 & 1 \\
\hline Apoio dos amigos & 7 & 9 \\
\hline Ligação à escola & 7 & 14 \\
\hline Apoio de pessoas significativas & 6 & 8 \\
\hline Avós & 2 & 3 \\
\hline Irmãos & 2 & 2 \\
\hline Namorado(a) & 1 & 1 \\
\hline Articulação escola-família & 5 & 7 \\
\hline Atividades extracurriculares & 4 & 4 \\
\hline \multicolumn{3}{|l|}{ Exossistema } \\
\hline Decisões acerca da vida dos filhos & 10 & 59 \\
\hline Continuidade na parentalidade e coparentalidade pré e pós separação & 10 & 18 \\
\hline Adequar as decisões às necessidades e características das crianças e da família & 8 & 28 \\
\hline Estabilidade & 6 & 13 \\
\hline \multicolumn{3}{|l|}{ Macrossistema } \\
\hline Maior aceitação social da separação e divórcio parental & 1 & 1 \\
\hline
\end{tabular}

resultaram 33 categorias interrelacionadas, organizadas num sistema hierárquico onde existem 10 categorias principais:

Quanto aos fatores de risco para a adaptação à separação parental os jovens identificaram como central a má relação entre os pais (10p-43r), mais concretamente expor e envolver os filhos nos conflitos dos pais $(8 \mathrm{p}-14 \mathrm{r})$ e dificultar a relação com outro progenitor $(7 \mathrm{p}-21 \mathrm{r})$ :

“...é o envio dos recadinhos "Olha, vais dizer ao teu pai não sei quê.". Pronto, tu chegas lá, és tu que estás a dizer pela outra pessoa. E isso é muito mau...". (F,27).

Apontaram também as dificuldades nas relações pais-filhos (5p-9r) como fator de risco, que relacionaram com as mudanças na parentalidade depois da separação:

“...o caso clássico é os pais divorciam-se e começam a permitir uma data de coisas que não permitiriam em fases normais aos filhos porque já sentem que lhes fizeram mal. E eu acho que isso, a longo prazo, se revela bastante negativo..." (F,23). 
Quadro 4. Árvore de categorias dos fatores de risco identificados pelos jovens adultos

\begin{tabular}{|c|c|c|}
\hline Fatores de risco & $\mathrm{N}^{\mathrm{o}}$ pessoas & $\mathrm{N}^{\circ}$ referências \\
\hline \multicolumn{3}{|l|}{ Microssistema } \\
\hline Relação entre pais & 10 & 43 \\
\hline Expor e envolver os filhos nos conflitos dos pais & 8 & 14 \\
\hline Dificultar a relação com o outro progenitor & 7 & 21 \\
\hline Excessiva proximidade entre os pais & 4 & 5 \\
\hline Relações cortadas & 1 & 2 \\
\hline Forçar o filho a estar com o outro progenitor & 1 & 1 \\
\hline Comunicação da decisão da separação & 6 & 7 \\
\hline Revelar demasiado acerca dos assuntos conjugais & 6 & 7 \\
\hline Relação pais-filhos & 5 & 9 \\
\hline Dificuldade na imposição de regras e limites & 2 & 4 \\
\hline Tentar comprar os filhos & 2 & 3 \\
\hline Filhos sentirem-se pouco importantes na vida dos pais & 1 & 1 \\
\hline Dificuldade em aceitar namoros dos filhos & 1 & 1 \\
\hline Idade dos filhos no momento da separação & 3 & 4 \\
\hline Pré-adolescência e adolescência & 3 & 4 \\
\hline Estar a estudar fora durante a separação & 1 & 1 \\
\hline \multicolumn{3}{|l|}{ Mesossistema } \\
\hline Família alargada & 6 & 7 \\
\hline Tomar partidos & 4 & 4 \\
\hline Dificuldade em aceitar a separação & 1 & 2 \\
\hline Confronto com a perda & 1 & 1 \\
\hline Escola & 2 & 3 \\
\hline Dificultar o envolvimento dos dois pais na vida escolar & 2 & 3 \\
\hline \multicolumn{3}{|l|}{ Exossistema } \\
\hline Decisões acerca da vida dos filhos & 8 & 16 \\
\hline Processo de tomada de decisões & 1 & 1 \\
\hline Não conversar com os filhos & 1 & 1 \\
\hline Tipo de residência & 8 & 15 \\
\hline Desvantagens da residência alternada & 7 & 13 \\
\hline Falta de estabilidade & 5 & 8 \\
\hline Necessidade do seu espaço & 3 & 4 \\
\hline Desvantagens da residência com um dos pais & 2 & 2 \\
\hline Menos proximidade de um dos pais & 2 & 2 \\
\hline \multicolumn{3}{|l|}{ Macrossistema } \\
\hline Família diferente da norma & 1 & 1 \\
\hline $\begin{array}{l}\text { Dificuldades burocráticas para as famílias cujos filhos vivem em residência } \\
\text { alternada }\end{array}$ & 1 & 1 \\
\hline
\end{tabular}

Quanto ao mesossistema, 4 jovens falaram no facto da família alargada tomar partidos como prejudicial:

"Ouvir comentários ... claramente dirigidos ao meu pai. Isso era das piores coisas.” (M,22).

No que diz respeito ao exossistema, nomeadamente às decisões tomadas acerca da vida dos filhos, os jovens focaram as desvantagens da residência alternada (7p-13r), nomeadamente a falta de estabilidade $(5 \mathrm{p}-8 \mathrm{r})$ e a necessidade do seu espaço (3p-4r), e apenas 2 referiram como desvantagem da residência com um dos progenitores a menor proximidade relacional com o progenitor não residente (2p2r). É importante sublinhar a forma pouco conclusiva como foram referidas as vantagens e desvantagens de cada tipo de residência.

\section{Comparação entre os fatores protetores identificados pelos magistrados e pelos jovens adultos}

Para ambas as amostras os fatores protetores identificados como mais relevantes no microssistema foram a qualidade da relação entre pais (9Magistrados/10Jovens-9M/10J) e da relação pais-filhos $(9 \mathrm{M} / 9 \mathrm{~J})$. Na relação entre pais ambas as amostras falaram acerca do respeito (4M/7J), da comunicação eficaz entre os pais $(2 \mathrm{M} / 7 \mathrm{~J})$ e da separação entre conjugalidade $e$ parentalidade $(2 \mathrm{M} / 6 \mathrm{~J})$ como protetores, sendo que apenas os magistrados falaram no tempo decorrido desde a rutura conjugal (4M) como fator protetor. Quanto à qualidade da relação pais-filhos os magistrados destacaram a importância das atitudes que protegem os filhos da situação (8M) e os jovens adultos concretizaram estas atitudes em apoio emocional 
(6J) e na manutenção dos papéis e da parentalidade (3J), sendo que ambas as amostras destacaram o maior envolvimento possível dos dois pais na vida dos filhos $(4 \mathrm{M} / 7 \mathrm{~J})$ como protetor neste processo de adaptação, embora mais os jovens. Apenas os jovens falaram acerca do efeito protetor do apoio dos amigos (7J), do suporte da comunidade escolar (7J) e do apoio de pessoas significativas (6J).

No mesossistema ambas as amostras apontaram o apoio da família alargada como fator protetor $(6 \mathrm{M} / 8 \mathrm{~J})$ e apenas os jovens falaram acerca da importância da articulação escolafamília (5J).

Em relação ao nível exossistémico, os fatores associados por ambos os grupos a critérios protetores na tomada das decisões acerca da vida dos filhos de pais separados foram a adaptação às necessidades e características das crianças e da família (5M/8J) e a importância da estabilidade $(8 \mathrm{M} / 6 \mathrm{~J})$. Outra temática que surgiu em todos os discursos dos jovens adultos acerca dos fatores protetores nas tomadas de decisão foi a importância da continuidade na parentalidade e coparentalidade pré e pós separação (10J). Este tema relaciona-se com os fatores protetores na tomada de decisões que os magistrados referiram: o acordo entre os pais (6M), o maior envolvimento possível dos dois pais na vida dos filhos $(6 \mathrm{M})$, e a relação entre os pais $(8 \mathrm{M})$ e com as definições de sucesso: situações em que os pais fazem o acordo entre si (7M) e em que se consegue compreender $e$ assegurar o superior interesse das crianças $(6 \mathrm{M})$.

Apenas os magistrados referiram como fatores protetores do exossistema, ferramentas para trabalhar os processos de regulação das responsabilidades parentais e a existência de advogados que fomentam a resolução dos conflitos (4M). No macrossistema houve mais magistrados a falar acerca de fatores protetores a este nível (6M) do que jovens adultos (1J).

\section{Comparação entre os fatores de risco identificados pelos magistrados e pelos jovens adultos}

Em relação aos fatores de risco na adaptação à separação parental no microssistema, os temas da relação entre os pais foram os mais referidos por ambas as amostras. Mais concretamente os magistrados falaram no conflito parental $(8 \mathrm{M})$ e os jovens adultos nas dificuldades na relação entre os pais (10J), especificando-a mais detalhadamente nas subcategorias. Ambas as amostras referiram também dificuldades nas relações-pais filhos $(2 \mathrm{M} / 5 \mathrm{~J})$.

No mesossistema a família alargada tomar partidos $(5 \mathrm{M} / 4 \mathrm{~J})$ foi o fator identificado por ambos os grupos, embora os jovens tenham identificado outros riscos associados à relação com a família alargada neste processo (2J).

A nível exossistémico, destacou-se o facto de 7 jovens adultos terem referido as desvantagens da residência alternada, mais concretamente da falta de estabilidade (5J) e da necessidade de ter o seu espaço (3J), mas apenas 3 magistrados falaram nas desvantagens deste tipo de residência, embora o motivo coincida, a instabilidade habitacional $(3 \mathrm{M})$. Ainda assim, é importante referir que apesar de apenas 2 jovens e 2 magistrados terem identificado uma desvantagem da residência com um dos progenitores, esta coincide e é a menor proximidade com o progenitor não residente $(2 \mathrm{M} / 2 \mathrm{~J})$. Ainda a este nível, apenas os magistrados identificaram fatores de risco para a conflitualidade nos processos, fatores de risco relacionados com os meios utilizados para trabalhar os processos (10M) e ainda a existência de advogados interessados em fomentar o conflito $(6 \mathrm{M})$.

Nas perceções acerca dos fatores de risco voltou a verificar-se que os magistrados identificaram mais fatores de risco macrossistémicos $(8 \mathrm{M})$ do que os jovens adultos (2J).

\section{Discussão}

Esta investigação pretende contribuir para o conhecimento das perceções de magistrados do TFM acerca dos principais fatores de proteção e de risco na adaptação à separação parental; aceder às perceções de jovens adultos com pais separados acerca dos fatores de risco e proteção na adaptação à separação parental e comparar as perceções de ambas as amostras, de modo a levantar hipóteses explicativas acerca do impacto dos diversos fatores no processo de adaptação à separação parental bem como das suas implicações práticas. 
Assim, torna-se relevante analisar a grande diversidade e riqueza destes dados, com potencial de contribuir para levantar hipóteses explicativas e alargar perspetivas acerca do processo de adaptação à separação parental.

Começando pelas perceções dos magistrados, no microssistema a qualidade da relação paisfilhos e da relação entre os pais foram os fatores protetores mais identificados e o conflito interparental o fator de risco mais referido. $\mathrm{O}$ efeito protetor da qualidade da relação entre pais e filhos, do apoio e sensibilidade dos pais e do envolvimento dos dois na vida dos filhos tem sido apontado por diversas investigações nesta área (e.g., Amato, 2000; Di Stefano \& Cry, 2014), o que sustenta os resultados aqui encontrados. $\mathrm{Na}$ relação entre os pais, os principais fatores protetores apontados pela literatura são a existência de uma relação de cooperação, de apoio e de paz, associada também à diminuição do conflito depois da separação (e.g., Kushner, 2009; Lamela et al., 2016; Lansford, 2009), o que é compatível com a categoria do respeito, associada à boa relação entre os pais. $\mathrm{O}$ efeito protetor do tempo decorrido desde a rutura conjugal referido pelos magistrados pode ser explicado, de acordo com Kelly e Emery (2003), pelo facto de, na maior parte dos pais separados, se verificar uma diminuição do conflito nos primeiros 2 a 3 anos após o divórcio, à medida que se vão desligando mais um do outro e que se envolvem na vida presente.

Quanto ao conflito inter-parental há uma sobreposição entre as categorias que emergem da análise do discurso dos magistrados e os dados da literatura, mais concretamente a ligação entre os níveis de conflito inter-parental elevados antes, durante e depois da separação e as dificuldades de adaptação dos filhos (e.g., Davies et al., 2012; Martínez-Pampliega et al., 2015). Destacam-se os efeitos nocivos do conflito elevado e explícito, que se centra nos filhos e dos conflitos de lealdade que levam à deterioração da relação com o outro progenitor (Amato, 2000; Kelly \& Emery, 2003; Birnbaum \& Saini, 2013), tal como o que foi referido pelos magistrados.

No mesossistema os magistrados e os jovens adultos focaram a relação com a família alargada, tanto o efeito protetor do suporte da família alargada como o risco da família alargada tomar partidos. Na literatura apenas foi possível encontrar forma de explicar os resultados relativos ao efeito protetor do suporte da família alargada (Amato, 2000; Eldar-Avidan et al., 2009; Gately \& Schwebel, 1991; Rodgers \& Rose, 2002). Quanto ao risco de tomar partidos e de se envolver no conflito, não foi possível encontrar investigação. Assim, este pode ser um dado relevante na medida em que ilustra situações em que a família pode, com ou sem intenção, fomentar o conflito entre os pais ou entre famílias, o que pode ter o potencial de dificultar a adaptação à separação parental.

No exossistema foram incluídos os fatores relacionados com o trabalho dos processos de regulação das responsabilidades parentais. De acordo com Fialho (2013), os magistrados assumem, sobretudo nas conferências de pais, um papel preponderante por terem a responsabilidade de conseguir um acordo entre os pais, tendo ao dispor várias formas de trabalho e recursos como a assessoria técnica ou parcerias com IPSS que poderão dar orientação técnica valiosa e constituir-se como fator protetor. Os magistrados referiram atitudes empáticas, práticas de negociação e ferramentas gestão de conflito como protetoras, contudo, todas elas foram associadas a características, experiências, valores e práticas pessoais do magistrado, o que, para o papel preponderante que desempenham nestes processos, pode ser um risco. Quanto aos recursos utilizados no trabalho dos magistrados, as IPSS e os CAFAP foram apontados como protetores, tal como referido na literatura (Fialho, 2013). Contudo, por outro lado, o tempo de espera pelos relatórios da Segurança Social e pelas perícias do Instituto de Medicina Legal foram enquadrados pelos magistrados como um fator de risco. Não foi possível encontrar na literatura estudos acerca do efeito protetor ou de risco associado às formas de trabalho e ferramentas do magistrado, o que faz com que a investigação acerca deste tema tenha grande pertinência e relevância dado o impacto que tem na prática.

De acordo com a Lei n. ${ }^{\circ} 61 / 2008$, de 31 de Outubro os critérios para a tomada de decisão do tribunal deverão ser o interesse dos filhos, o eventual acordo entre os pais e a disponibilidade manifestada por cada progenitor para promover a relação dos filhos com o outro progenitor, dada a 
importância da manutenção de uma relação de proximidade com ambos os pais. Conclui-se que as perceções dos magistrados acerca dos critérios protetores na tomada de decisão (estabilidade, da relação entre os pais, do maior envolvimento possivel dos dois pais na vida dos filhos, do acordo entre os pais e da adaptação à realidade da família) e acerca das situações de sucesso (os pais fazerem o acordo entre si e compreender e assegurar o superior interesse das crianças) vão ao encontro do que está definido na lei e com os principais fatores protetores identificados na literatura (Amato, 2000).

Salientaram também o papel dos advogados, que, de acordo com a sua atitude face ao conflito, podem constituir-se como fator de risco ou proteção. Não tendo sido possível encontrar estes dados na literatura, esta pode ser uma boa pista a incluir em investigação futura.

Em relação à perceção dos magistrados acerca da intensidade e frequência da conflitualidade nestes processos (famílias com mais poder económico, o desacordo nas questões de contactos e residência sendo o mais frequente conflitos pela pensão de alimentos) e, não tendo sido possível encontrá-los na literatura consultada, foi possível conjeturar várias hipóteses explicativas dos mesmos com base nas perceções dos magistrados. A primeira hipótese é a de existindo maior disponibilidade económica para assegurar os custos inerentes ao prolongamento do processo em tribunal, se mantenha o conflito em tribunal durante mais tempo. Por outro lado, a contratação de advogados pelas partes pode ter como consequência a complexificação dos processos e a existência de maior interesse na manutenção do conflito. A terceira hipótese é a de que pessoas com mais escolaridade utilizem recursos mais elaborados para o conflito, como o litígio em tribunal.

$\mathrm{O}$ facto de os contactos pessoais e a residência serem, na perspetiva dos magistrados, o motivo que gera mais conflitualidade, compadece-se com a perspetiva de que na negociação da nova configuração das relações, formato e papéis na família estas possam ser questões com implicações emocionais fortes. Os conflitos cada vez mais frequentes acerca da pensão de alimentos podem também estar relacionados com a atual crise socioeconómica que ainda se vive, aliada à maior fragilidade financeira das famílias que se separam (Lansford, 2009).

Por fim, em relação ao macrossistema, a proposta dos magistrados para a formação de equipas multidisciplinares a funcionar no tribunal pode estar relacionada com as suas perceções do funcionamento e articulação do sistema social com o sistema judicial, como demoras nos relatórios da Segurança Social e do Instituto de Medicina Legal e a escassez de apoio técnico. A presença de equipas multidisciplinares no tribunal (em que alguns incluem a mediação familiar) é apontada como uma resposta mais vantajosa pelos magistrados pela facilidade de acesso, pelo trabalho em rede, pela maior rapidez e pela diversidade de respostas que concorreriam para uma resolução mais eficaz e pacificadora dos conflitos familiares.

Os resultados do presente estudo que dizem respeito aos efeitos protetores e de risco da relação entre os pais na adaptação à separação parental encontram-se muito bem fundamentados na literatura, sobretudo os efeitos nocivos de uma má relação (e.g., Amato, 2000; Kelly \& Emery, 2003; Kushner, 2009; Lamela et al., 2016). Dificultar a relação dos filhos com o outro progenitor e usá-los para o atingir (Davies et al., 2012; Lansford, 2009), bem como dizer mal do outro progenitor aos filhos (Kelly \& Emery, 2003) têm sido fortemente apontados como fatores de risco relevantes no processo de adaptação, o que também vai ao encontro dos resultados do presente estudo.

Dos resultados obtidos através das perceções dos jovens adultos quanto à relação pais-filhos, diversos estão sustentados na literatura, com destaque para o efeito protetor do envolvimento dos dois pais na vida dos filhos depois da separação e do efeito nocivo para as relações de envolver os filhos nos conflitos dos pais (e.g., Davies et al., 2012; Holt, 2016). Alguns autores vão ao encontro do que foi referido pelos jovens acerca da importância da manutenção da parentalidade após a separação, dado que as dificuldades na imposição de regras e limites e a compensação dos filhos pela separação são estratégias parentais com efeitos nocivos no seu desenvolvimento (Amato, 2000; Di Stefano \& Cry, 2014; Holt, 2016).

De acordo com Kelly e Emery (2003), o impacto 
da comunicação da decisão da separação parental no processo de adaptação dos filhos a esta realidade tem sido mais estudado pelas suas consequências negativas. Concluiu-se que estas ocorrerem quando, durante o processo de comunicação, falta o espaço para dar significado e sentido a este acontecimento na vida dos filhos, quando as incertezas em relação às mudanças reinam e quando não há abertura para conversar sobre o assunto. Apesar de terem sido abordados pela positiva, todos os aspetos acima referidos foram mencionados pelos jovens: transmissão de informações e explicações claras acerca das mudanças, uso de linguagem e explicações adaptadas à idade dos filhos, transmissão de continuidade na relação com os pais e de segurança e vantagens da comunicação ser feita pelos dois pais.

Os jovens referiram ainda o efeito protetor do apoio da família alargada, a importância do apoio dos amigos, do suporte da comunidade escolar e de pessoas significativas como os avós, irmãos ou namorado/a, o que tem sido sustentado pela investigação (Amato, 2000; Birnbaum \& Saini, 2013; Eldar-Avidan et al., 2009; Gately \& Schwebel, 1991). Rodgers e Rose (2002) e Kushner (2009) justificam ainda a importância das atividades extracurriculares para a adaptação à separação parental como sendo um facilitador do desenvolvimento de competências sociais e de uma rede social de apoio, o que vai ao encontro das perceções dos jovens adultos entrevistados.

No mesossistema os jovens adultos referiram a articulação escola-família como um fator protetor, sugerindo que esta possa funcionar como suporte e retaguarda dos filhos/alunos que enfrentam mudanças e desafios adicionais.

Dos resultados encontrados no exossistema há a realçar que as perspetivas acerca do processo de tomada de decisões na vida dos filhos depois da separação (assegurar a continuidade na parentalidade pré e pós separação, a adequação das decisões às necessidades e características das crianças e da família e a estabilidade) se enquadram no que a investigação revela acerca da importância da parentalidade na adaptação à separação dos pais (Di Stefano \& Cry, 2014; Holt, 2016; Vélez et al., 2011). Isto ajuda também a compreender a dispersão das perceções dos jovens adultos acerca dos regimes de residência, dado que, de acordo com Amato (2000) a relação paisfilhos e a coparentalidade parecem estar bem mais relacionados com a adaptação e bem-estar dos filhos do que o tipo de residência. Kelly e Emery (2003) acrescentam ainda como fator protetor na adaptação à separação dos pais a satisfação dos filhos em relação à modalidade de residência e de exercício das responsabilidades parentais, o que ficou ilustrado nos resultados deste estudo exploratório.

\section{Diferenças e semelhanças nas perceções das duas amostras}

Em relação às principais semelhanças entre as perceções das duas amostras quanto aos fatores de risco para a adaptação à separação parental, tal como é apontado na literatura (Birnbaum \& Saini, 2013), os efeitos nocivos de práticas de triangulação e de fronteiras difusas entre o sistema conjugal e parental apareceram como categoriais centrais para ambas as amostras (usar os filhos como forma de atingir o outro, dificultar a relação com o outro progenitor e expor ou envolver os filhos no conflito). Ainda nesta linha, mas a um nível exossistémico, surgiu o papel nocivo que a família alargada pode ter ao tomar partidos ou partes neste conflito, o que revela também fronteiras difusas entre estes dois sistemas. Este funcionamento tem repercussões negativas para o desenvolvimento, bem-estar e saúde mental de pessoas e famílias (Alarcão, 2002).

Quanto aos fatores protetores, as maiores semelhanças encontradas foram a relação de respeito entre os pais, que emerge da capacidade de separar a parentalidade da conjugalidade, o que permite a flexibilidade necessária para o envolvimento dos dois pais na vida dos filhos. Ou seja, a capacidade para a família se reorganizar através das mudanças necessárias face ao fim da relação conjugal, sem prejuízo do funcionamento dos restantes sub-sistemas familiares, podendo abrir a possibilidade a processos de crescimento e aprendizagem (Lamela et al., 2016).

As diferenças encontradas nos resultados dos dois grupos são, principalmente, o facto dos jovens adultos terem referido mais fatores microssistémicos uma vez que os viveram de forma direta, enquanto os magistrados do TFM se focaram mais em fatores que dizem respeito às suas vivências, pertencentes ao exossistema. Além 
disso, o próprio guião das entrevistas convidava a que as pessoas falassem das suas experiências mais diretas de modo a aceder às vozes dos participantes relativamente ao fenómeno em estudo.

\section{Limitações e implicações}

Assim, a presente investigação levanta algumas pistas que podem vir a ajudar na compreensão mais alargada da adaptação dos filhos à separação parental, tendo em conta perspetivas de magistrados do TFM da área da grande Lisboa, o que se torna particularmente relevante dado que não foi possível encontrar investigações com estas características.

É fundamental ler os contributos e conclusões da presente investigação à luz das suas limitações. Em primeiro lugar, as amostragens por conveniência e por bola de neve utilizadas constituem, por si só, uma limitação, dado que os participantes não foram selecionados aleatoriamente, o que faz com que as conclusões do estudo não estejam em condições de ser generalizadas à população (Vanderstoep \& Johnson, 2009). Para isto concorre também a dimensão reduzida das amostras, que serve apenas o propósito de um estudo qualitativo de natureza exploratória como este, que tem o propósito de contribuir para abrir caminhos e deixar pistas para a investigação e prática.

Quanto aos instrumentos, é relevante referir que a entrevista semi-estruturada, apesar das suas vantagens, está dependente da relação estabelecida entre entrevistador e entrevistado, da forma como é conduzida e da subjetividade que lhe é inerente. Esta questão estende-se ao método da análise temática indutiva, por ser o investigador a criar categorias com base nos padrões que emergem dos conteúdos manifestos e latentes, e, apesar de ser feito com orientação e discutido com outra investigadora, implica subjetividade (Braun \& Clarke, 2006).

Em relação às amostras é importante ter em atenção a homogeneidade do nível de escolaridade elevado dos jovens adultos e das suas situações familiares estáveis, o que pode ter impacto nos resultados. Na amostra dos magistrados do TFM é importante considerar que temos apenas dados referentes aos que aceitaram participar na entrevista, o que pode indicar maior disponibilidade destes para refletir e expor o seu trabalho.

Apesar destas limitações, o contributo científico deste estudo exploratório qualitativo não deixa de ser relevante, trazendo implicações para a investigação e prática. Em primeiro lugar, continua a verificar-se a necessidade de conhecer aprofundadamente, tendo em conta estes resultados, os mecanismos através dos quais a família se reorganiza depois da separação conjugal e o papel que os fatores identificados desempenham.

Por outro lado, devido à necessidade crescente de dar resposta a estas famílias e de alargar a investigação desta área em Portugal, seria pertinente o desenvolvimento ou adaptação de uma escala para medir a adaptação à separação parental. Apesar de existirem bons instrumentos psicométricos para medir o ajustamento e o bemestar de forma não patologizante em jovens adultos (Cunha, Silva, Vilaça, Gonçalves, \& Relvas, 2014; Figueira, Pinto, Lima, Matos, \& Cherpe, 2014) seria muito pertinente, com base nos instrumentos existentes e nos dados da literatura acerca deste tema, que fosse construído ou adaptado para Portugal um instrumento específico para medir as adaptação e ajustamento à separação parental, com implicações fundamentais para a investigação e para a prática.

$\mathrm{O}$ estudo aponta ainda para a pertinência de intervenções em grupo para crianças com os pais separados, como a intervenção de Almeida e Monteiro (2012), e traz uma outra grande implicação prática, a necessidade da generalização do recurso à Mediação Familiar para dar resposta ao que a literatura e este estudo apontam como fundamental na adaptação à separação dos pais: a modificação e pacificação das relações entre pais, separar a parentalidade da conjugalidade e a construção de uma solução de exercício de responsabilidades parentais entre os pais que seja adaptada à realidade da família (Gomes \& Ribeiro, 2014).

\section{Referências}

Ahrons, C. R. (2008). The good divorce: Keeping your family together when your marriage comes apart. Pymble, NSW: HarperCollins. 
Alarcão, M. (2002). (des)Equilíbrios familiares: Uma visão sistémica (2a ed.). Coimbra: Quarteto.

Alarcão, M. (2007). Novas formas de família, novas formas de terapia? Em A. P. Relvas, \& M. Alarcão (Eds.), Novas formas de família ( $2^{\text {a }}$ ed., pp. 13-51). Coimbra: Quarteto.

Almeida, N., \& Monteiro, S. (2012) Os meus pais já não vivem juntos: Intervenção em grupo com crianças e jovens de pais divorciados. Lisboa: Coisas de Ler.

Amato, P. R. (2000). The consequences of divorce for adults and children. Journal of Marriage and Family, 62(4), 1269-1287.

Amato, P. R., Loomis, L. S., \& Booth, A. (1995). Parental divorce, marital conflict, and offspring well-being during early adulthood. Social Forces, 73, 895. doi: $10.2307 / 2580551$

Associação Portuguesa para a Igualdade Parental e Direito dos Filhos. (2012). Estatísticas da justiça de família e menores: Análise de dados estatísticos de 2011. Acedido a 10 de Outubro de 2014 em http://igualdadeparental.org/wpcontent/uploads/2013/03/Estat\%C3\%ADsticas -dos-Tribunais-de-Fam\%C3\%ADlia-eMenores-Portugueses-2011_versaofinal.pdf

Bertalanffy, L. V. (1950). An outline of general system theory. The British Journal for the Philosophy of Science, I(2), 134-165. Acedido a 7 de Dezembro de 2013 em http://dx.doi.org/10.1093/bjps/I.2.134.

Blankenhorn, D. (1995). Fatherless America: Confronting our most urgent social problem.

Braun, V., \& Clarke, V. (2006). Using thematic analysis in psychology. Qualitative Research in Psychology, 3(2), 77-101.

Bronfenbrenner, U. (1979). The ecology of human development: experiments by nature and design. Cambridge, Mass.: Harvard University Press.

Bronfenbrenner, U. (1986). Ecology of the family as a context for human development: Research perspectives. Developmental Psychology, 22(6), 723-742.

Cunha, D., Silva, J. T., Vilaça, M., Gonçalves, S., \& Relvas, A. P. (2014). Escala de congruência (EC): Estudos de adaptação para a população portuguesa. $=$ Congruence scale (CS): adaptation studies for the portuguese population. Revista Iberoamericana de Diagnóstico y Evaluación - e Avaliação Psicológica, 38(2), 181-197.

Decreto-lei no 61/2008 de 31 de Outubro. Diário da República: I série, No 212 (2008). Acedido a 20 de Março de 2017 em http://www.dgpj.mj.pt/sections/noticias/lei-n61-2008-de-31-de.

Eldar-Avidan, D., Haj-Yahia, M. M., \& Greenbaum, C. W. (2009). Divorce is a part of my life... resilience, survival, and vulnerability: Young adults' perception of the implications of parental divorce. Journal of Marital \& Family Therapy, 35, 30-46. doi:10.1111/j.1752-0606.2008.00094.x

Erikson, E. H. (1963). Eight ages of the man. Childhood and society (2d ed., pp. 222-243). New York: Norton.

Fialho, A. J. (2013). Guia prático do divórcio e das responsabilidades parentais ( $2^{\mathrm{a}}$ ed.). Lisboa: Centro de Estudos Judiciários.

Figueira, C., Pinto, A. M., Lima, L., Matos, A. P., \& Cherpe, S. (2014). Adaptação do mental health continuum-Lf-for adults em estudantes universitários Portugueses $=$ Adapting the mental health continuum-Lf-for adults in Portuguese university students. Revista Iberoamericana de Diagnóstico y Evaluación - e Avaliação Psicológica, 38(2), 93-116.

Friendly, R. W., \& Grolnick, W. S. (2008). Child adjustment to familial dissolution: An examination of parental factors using a selfdetermination theory framework. Journal of Divorce \& Remarriage, 50(1), 66-80.

Gately, D. W., \& Schwebel, A. I. (1991). The challenge model of children's adjustment to parental divorce: Explaining favorable postdivorce outcomes in children. Journal of Family Psychology, 5(1), 60-81.

Gomes, L. \& Ribeiro, M. T. (2014). Mediação familiar e conflito parental: Uma análise interdisciplinar sobre modelos teóricos de intervenção. In M. T. Ribeiro, P. T. Matos, \& H. R. Pinto (Eds.), Mediação Familiar: Contributo de investigações realizadas em Portugal (pp. 13-31). Lisboa: Universidade Católica Editora.

Guedeney, N., \& Guedeney, A. (2004). Vinculação e adolescência. In Climepsi Editores (Eds.), Vinculação: Conceitos $e$ 
Aplicações (pp. 147-156). Lisboa: Climepsi Editores. (Original work published 2002).

Hetherington, E., \& Stanley-Hagan, M. (1999). The adjustment of children with divorced parents: a risk and resiliency perspective. Journal of Child Psychology \& Psychiatry \& Allied Disciplines, 40, 129-140. doi:10.1111/1469-7610.00427

Kelly, J. B., \& Emery, R. E. (2003). Children's adjustment following divorce: Rrisk and resilient perspectives. Family Relations, 52(4), 352-362.

Kushner, M. A. (2009). A Review of the empirical literature about child development and adjustment postseparation. Journal of Divorce \& Remarriage, 50(7), 496-516.

Lansford, J. E. (2009). Parental divorce and children's adjustment. Perspectives on Psychological Science, 4(2), 140-152.

Magnavita, J. J. (2012). Advancing clinical science using system theory as the framework for expanding family psychology with unified psychotherapy. Couple and Family Psychology: Research and Practice, 1(1), 313.

Marks, D., \& Yardley, L. (2004). Research methods for clinical and health psychology. London: SAGE.

Nielsen, L. (2013). Shared residential custody: Review of the research (Part I of II). American Journal of Family Law, 27(2), 6171.

Nielsen, L. (2014). Shared physical custody: Summary of 40 studies on outcomes for children. Journal of Divorce \& Remarriage, 55, 613-635. doi: 10.1080/10502556.2014.965578

Peck, J. S., \& Manocherian, J. R. (1989). Divorce in the changing family life cycle. In Carter, E. A., \& McGoldrick, M., The Changing family life cycle: a framework for family therapy (2nd ed., pp. 335-369). Boston: Allyn and Bacon.

Pordata (2017a). Agregados domésticos privados: total e por tipo de composição. Acedido a 9 de $\begin{array}{llll}\text { Março de } & 2017 & \text { em }\end{array}$ https://www.pordata.pt/Portugal/Agregados $+\mathrm{d}$ om\%C3\%A9sticos+privados+total+e+por+tip o+de+composi\%C3\%A7\%C3\%A3o+-19.

Pordata (2017b). Número de divórcios por 100 casamentos em Portugal. Acedido a 9 de $\begin{array}{llll}\text { Março de } & 2017 & \text { em }\end{array}$ https://www.pordata.pt/Portugal/N\%C3\%BA mero+de+div\%C3\%B3rcios+por+100+casam entos-531.

Ricci, I. (2004). Casa da mãe, casa do pai. Construir dois lares para os seus filhos. Um guia para pais separados, divorciados ou que voltaram a casar. Lisboa: Ed. Sílabo.

Rodgers, K. B., \& Rose, H. A. (2002). Risk and resiliency factors among adolescents who experience marital transitions. Journal of Marriage and Family, 64, 1024-1037.

VanderStoep, S. W., \& Johnston, D. D. (2009). Research methods for everyday life: Blending qualitative and quantitative approaches. San Francisco, CA: Jossey-Bass.

Vélez, C. E., Wolchik, S. A., Tein, J., \& Sandler, I. (2011). Protecting children from the consequences of divorce: A longitudinal study of the effects of parenting on children's coping processes. Child Development, 82(1), 244-257.

Wallerstein, J. S. (1983). Children of divorce: The psychological tasks of the child. American Orthopsychiatric Association, 53(2), 230-243. 